\title{
Hubungan Aktivitas Fisik Harian dengan Gangguan Menstruasi pada Mahasiswa Fakultas Kedokteran Universitas Andalas
}

\author{
Putri Anindita ${ }^{1}$, Eryati Darwin ${ }^{2}$, Afriwardi $^{3}$
}

\begin{abstract}
Abstrak
Gangguan menstruasi dapat menimbulkan stres dan menurunkan kualitas hidup wanita. Gambaran menstruasi seseorang dapat memperlihatkan keadaan fungsi reproduksi seseorang dan risiko mengalami berbagai penyakit. Aktivitas fisik diperkirakan sebagai salah satu cara untuk mengurangi terjadinya gangguan menstruasi tersebut. Tujuan penelitian ini adalah menentukan hubungan antara aktivitas fisik harian dan gangguan menstruasi. Desain penelitian menggunakan cross sectional study dengan jumlah subjek 90 mahasiswi Fakultas Kedokteran Universitas Andalas Angkatan 2011-2013. Data didapatkan dari kuisioner yang diisi langsung oleh masing-masing responden yang kemudian dianalisis denga uji chi-square. Hasil penelitian mendapatkan gangguan menstruasi terjadi pada $73,3 \%$ mahasiswi dengan gangguan yang paling sering terjadi yaitu dysmenorrhea sebanyak $63,3 \%$. Sebagian besar mahasiswi tersebut memiliki aktivitas fisik harian yang cukup menurut rekomendasi WHO yaitu sebanyak $60 \%$. Berdasarkan uji chi-square, tidak ditemukan adanya hubungan antara aktivitas fisik harian dan gangguan menstruasi $(p=0,846)$. Kesimpulan ialah tidak terdapat hubungan yang bermakna antara aktivitas fisik harian dan gangguan menstruasi pada mahasiswi Fakultas Kedokteran Universitas Andalas.
\end{abstract}

Kata kunci: aktivitas fisik, gangguan menstruasi, mahasiswi FK

\begin{abstract}
Menstrual disorder is often cause stress and decrease the life quality of a woman. Menstrual pattern can describe the condition of reproduction function and risk of having several disease. Physical Activity is considered as one of the way to reduce menstrual disorder. The objective of this study was to determine the association between daily physical activity and menstrual disorder. This study used cross sectional design on 90 female medical student of Andalas University Class of 2011-2013 as the sample. The data from self reported questionnaire that was given to the students is analyzed using chi-square. The results show that menstrual disorder is occured in 73,3\% of the female medical student and the most frequent disorder is dysmenorrhea 63,3\%. Most of the students are physically active correspond to the recommendation of WHO about $60 \%$. It is inferred that there is no association between daily physical activity and menstrual disorder $(p=0,846)$. The conclusion is daily physical activity and menstrual disorder among female medical students in Andalas University have no significant association.
\end{abstract}

Keywords: physical activity, menstrual disorder, female medical student

Affiliasi penulis: 1. Prodi Profesi Dokter FK UNAND (Fakultas Kedokteran Universitas Andalas Padang), 2. Bagian Histologi FK UNAND, 3. Bagian Fisiologi FK UNAND.

Korespondensi: Putri Anindita,Email: putri.anindita@ymail.com, Telp: 085263370542

\section{PENDAHULUAN}

Menstruasi adalah proses deskuamasi lapisan uterus yang terjadi setiap bulan pada wanita. ${ }^{1}$ Gangguan menstruasi dapat berupa gangguan ritme 
menstruasi, kelainan kuantitas serta durasi menstruasi, amenorrhea dan dysmenorrhea. ${ }^{2,3}$

Gangguan menstruasi kebanyakan dialami oleh wanita pada masa remaja akhir. ${ }^{4}$ Lima puluh persen wanita mengalami gangguan menstruasi pada dua tahun pertama setelah menarche. Pada empat sampai lima tahun setelah menarche, kejadian gangguan menstruasi menurun namun menetap pada $20 \%$ wanita. ${ }^{3,4}$ Penelitian Sianipar et al diketahui bahwa $63,2 \%$ dari siswa SMU di Jakarta Timur yang berumur 15-19 tahun mengalami gangguan menstruasi. Pada sebuah universitas di Jakarta, 83,5\% mahasiswa mengalami dismenorrhea. Tujuh puluh enam persen dokter yang menerima kasus gangguan menstruasi beranggapan bahwa kasus tersebut perlu dirujuk, namun hanya $37 \%$ wanita yang merasa bahwa gangguan menstruasi adalah masalah. ${ }^{5}$

Gangguan menstruasi dapat menurunkan kualitas hidup wanita. Pada pekerja di Amerika, angka kehadiran dan jumlah pendapatan pertahun wanita lebih rendah dibandingkan dengan pria, karena wanita mengalami gangguan menstruasi. ${ }^{6}$ Siklus menstruasi dapat digunakan sebagai indikator untuk mengetahui fungsi reproduksi (fertilitas), prediksi kanker payudara, risiko penyakit kardiovaskuler dan osteoporosis. ${ }^{7,8}$

Hal-hal yang dapat mempengaruhi siklus menstruasi, yaitu: kondisi patologis (contohnya Polycystic Ovarian Syndrome), gaya hidup (misalnya kebiasaan merokok, konsumsi alkohol, malnutrisi dan aktivitas fisik) dan kondisi psikologis (seperti depresi dan ansietas). ${ }^{4}$ Aktivitas fisik merupakan salah satu faktor yang dapat dimodifikasi dengan mudah. Aktifitas fisik tidak harus dalam bentuk olahraga berat untuk meningkatkan derajat kesehatan, melainkan dapat berupa aktivitas saat di tempat kerja, dalam perjalanan, melakukan pekerjaan rumah dan olahraga rekreasi. $^{9}$

Aktivitas fisik berperan penting dalam usaha pencegahan penyakit tidak menular. Terutama pada negara berkembang yang sebagian besar dari total pengeluaran energi masyarakatnya digunakan dalam bekerja dan transportasi daripada olahraga rekreasi. ${ }^{10}$ Olahraga teratur dapat mengatasi dismenorrhea, mencegah obesitas, mengurangi risiko kanker payudara. $^{11-13}$
Tujuan penelitian ini adalah menentukan hubungan antara aktivitas fisik harian dan gangguan menstruasi pada mahasiswa Fakultas Kedokteran Universitas Andalas.

\section{METODE}

Penelitian telah dilakukan pada mahasiswi Fakultas Kedokteran Universitas Andalas Angkatan 2011-2013 dengan menggunakan kuisioner mengenai riwayat menstruasi dan Global Physical Activity Questionnaire dari World Health Organization (WHO). Sampel yang digunakan pada penelitian ini adalah mahasiswi berusia 17-20 tahun, telah mengalami menstruasi, Body Mass Index (BMI) normal, tidak mengalami penyakit organ reproduksi, tidak merokok, dan tidak depresi. Pemilihan subjek dilakukan dengan menggunakan teknik simple random sampling.

\section{HASIL}

Pembagian kuisioner didapatkan sebanyak 345 responden. Dari 345 responden tersebut terdapat 24 responden yang tidak lengkap mengisi kuisioner dan hanya 104 yang memenuhi kriteria inklusi dan eksklusi. Jumlah tersebut dimasukkan ke dalam rumus sampel dan didapatkan jumlah sampel sebanyak 90 orang.

Tabel 1. Karakteristik subyek penelitian

\begin{tabular}{|c|c|c|}
\hline Variabel & $f$ & Rerata \pm SD \\
\hline \multicolumn{3}{|l|}{ Umur } \\
\hline 17 & $9(2,8 \%)$ & \\
\hline 18 & $79(24,6 \%)$ & \\
\hline 19 & $108(33,6 \%)$ & \\
\hline 20 & $74(23,1 \%)$ & \\
\hline 21 & $30(9,3 \%)$ & \\
\hline 22 & $21(6,5 \%)$ & \\
\hline \multicolumn{3}{|l|}{ BMI } \\
\hline$<18,5$ & $56(17,4 \%)$ & \\
\hline $18,5-24,9$ & $236(73,5 \%)$ & \\
\hline$>24,9$ & $29(9,0 \%)$ & \\
\hline \multicolumn{3}{|l|}{ Depresi } \\
\hline Tidak depresi & $184(57,3 \%)$ & \\
\hline Depresi ringan & $136(42,4 \%)$ & \\
\hline Depresi berat & $1(0,3 \%)$ & \\
\hline Usia menarche & & $13 \pm 2$ \\
\hline Belum pernah menstruasi & $0(0 \%)$ & \\
\hline Merokok & $0(0 \%)$ & \\
\hline
\end{tabular}


Tabel 1 menunjukkan karakteristik sampel yang sesuai dengan kriteria penelitian yaitu umur remaja akhir dengan usia terbanyak 19 tahun (33,6\%), BMI terbanyak yaitu 18,5-24,9 (73,5\%), 184 responden tidak mengalami depresi $(57,3 \%)$ dan usia menarche rata-rata adalah 13 tahun.

Tabel 2. Distribusi frekuensi gangguan menstruasi responden

\begin{tabular}{ccc}
\hline Menstruasi & $\mathbf{f}$ & $\%$ \\
\hline Normal & 24 & 26,7 \\
Gangguan & 66 & 73,3 \\
\hline Total & 90 & 100,0 \\
\hline
\end{tabular}

Berdasarkan Tabel 2 diketahui bahwa sebagian besar mahasiswa yang mengalami gangguan menstruasi yaitu sebanyak 66 orang $(73,3 \%)$.

Tabel 3. Distribusi frekuensi gangguan menstruasi responden berdasarkan jenis gangguan

\begin{tabular}{lcc}
\hline Menstruasi & $\mathbf{f}$ & $\%$ \\
\hline Normal & 24 & 26,7 \\
Gangguan & & \\
Oligomenorrhea & 2 & 4,4 \\
Polymenorrhea & 3 & 3,3 \\
Metrorrhagia & 1 & 1,1 \\
Hypomenorrhea & 0 & 0,0 \\
Menorrhagia & 7 & 7,8 \\
Amenorrhea sekunder & 3 & 3,3 \\
Dysmenorrhea & 57 & 63,3 \\
\hline Total & 90 & 100,0 \\
\hline
\end{tabular}

Tabel 3 menunjukkan bahwa gangguan yang paling banyak terjadi pada mahasiswa Fakultas Kedokteran Universitas Andalas adalah dysmenorrhea $(63,3 \%)$.

Tabel 4. Distribusi frekuensi dysmenorrhea pada responden berdasarkan lama nyeri

\begin{tabular}{ccc}
\hline Lama Nyeri & $\mathbf{f}$ & $\%$ \\
\hline 1 hari & 23 & 40,3 \\
2 hari & 33 & 57,9 \\
$>2$ hari & 1 & 1,7 \\
\hline Total & 57 & 100,0 \\
\hline
\end{tabular}

Tabel 4 menunjukkan bahwa lama nyeri paling banyak terjadi pada responden adalah 2 hari $(57,9 \%)$.
Tabel 5. Distribusi frekuensi dysmenorrhea pada responden berdasarkan konsumsi obat

\begin{tabular}{ccc}
\hline Konsumsi Obat & $\mathbf{f}$ & $\%$ \\
\hline Ya & 12 & 21,1 \\
Tidak & 45 & 78,9 \\
\hline Total & 57 & 100,0 \\
\hline
\end{tabular}

Tabel 5 menunjukkan bahwa sebagian besar responden yang mengalami dysmenorrhea tidak mengonsumsi obat.(78,9\%).

Tabel 6. Distribusi frekuensi aktivitas fisik pada responden

\begin{tabular}{ccc}
\hline Aktifitas fisik & $\mathbf{f}$ & $\%$ \\
\hline Cukup & 54 & 60.0 \\
Kurang & 36 & 40.0 \\
\hline Total & 90 & 100.0 \\
\hline
\end{tabular}

Pada Tabel 6 diketahui bahwa lebih dari separuh (60\%) mahasiswa Fakultas Kedokteran Universitas Andalas memiliki aktivitas harian cukup.

Tabel 7. Hubungan antara aktivitas fisik dengan gangguan menstruasi

\begin{tabular}{|c|c|c|c|c|c|c|c|}
\hline \multirow{3}{*}{$\begin{array}{c}\text { Aktifitas } \\
\text { Fisik }\end{array}$} & \multicolumn{6}{|c|}{ Gangguan Menstruasi } & \multirow{3}{*}{ p } \\
\hline & \multicolumn{2}{|c|}{ Tidak } & \multicolumn{2}{|c|}{ Ada } & \multicolumn{2}{|c|}{ Total } & \\
\hline & $f$ & $\%$ & $f$ & $\%$ & $f$ & $\%$ & \\
\hline Cukup & 14 & $26 \%$ & 40 & $74 \%$ & 54 & $100 \%$ & \multirow{2}{*}{0.846} \\
\hline Kurang & 10 & $28 \%$ & 26 & $72 \%$ & 36 & $100 \%$ & \\
\hline Total & 24 & $27 \%$ & 66 & $73 \%$ & 90 & $100 \%$ & \\
\hline
\end{tabular}

Pada Tabel 7 terlihat bahwa presentasi gangguan menstruasi lebih tinggi pada responden dengan aktivitas fisik yang cukup daripada responden dengan aktivtas fisik kurang (74\% berbanding $72 \%$ ). Berdasarkan uji chi-square diketahui nilai $p>0,05$ yang berarti secara statistik tidak berhubungan.

\section{PEMBAHASAN}

Sebagian besar mahasiswi mengalami gangguan menstruasi yaitu sebanyak 73,3\%. Pada penelitian Sianipar et al didapatkan jumlah gangguan menstruasi yaitu $63,2 \%$ pada siswa SMU "X" di Jakarta yang berusia 15-19 tahun. Gangguan menstruasi yang diteliti pada penelitian tersebut adalah gangguan siklus menstruasi, gangguan volume 
menstruasi, gangguan lama menstruasi dan gangguan lain yang berhubungan dengan menstruasi. Apabila kedua penelitian ini dibandingkan, terlihat bahwa kejadian gangguan menstruasi pada penelitian Sianipar et al lebih rendah. Hal ini diperkirakan terjadi karena perbedaan stressor pada mahasiswa dan siswa SMU. ${ }^{5}$

Responden dengan umur dibawah 22 tahun akan sering mengalami gangguan menstruasi. Hal ini disebabkan oleh siklus anovulasi yang sering terjadi pada kelompok umur tersebut yaitu sekitar 9\%-70\%. Pada masa remaja terjadi pematangan sistim endokrinologi yang dapat mempengaruhi interaksi hipotalamus dan ovarium. Waktu pematangan tersebut berbeda-beda setiap individu. Gangguan menstruasi akan lebih sering terjadi pada remaja wanita yang lebih muda dan kejadian tersebut akan berkurang seiring dengan bertambahnya usia. Gangguan ini sering terjadi pada 3-5 tahun setelah menarche. ${ }^{14,15}$

Gangguan yang paling banyak dialami oleh responden adalah dysmenorrhea (63,3\%). Pada penelitian Lee et al didapatkan bahwa 69,4\% remaja berusia 12-19 tahun di Negeri Sembilan, Malaysia mengalami dysmenorrhea. ${ }^{4}$ Pada penelitian Rianda didapatkan kejadian dysmenorrhea yang lebih tinggi yaitu sebanyak $84,7 \%$ pada mahasiswa Fakultas Kedokteran Universitas Sumatera Utara yang berusia 17-21 tahun. $^{16}$

Pada beberapa penelitian tersebut sebagian besar mahasiswi mengalami dysmenorrhea. Dysmenorrhea primer yang muncul tanpa adanya gangguan atau kelainan reproduksi sering terjadi pada usia remaja dan kejadiannya semakin menurun seiring dengan meningkatnya usia seseorang. Dysmenorrhea pada penelitian ini terjadi pada responden dengan rentang usia 17-20 tahun dan rerata usia menarche adalah 13 tahun. Apabila dysmenorrhea muncul pada usia yang jauh lebih lama setelah usia menarche maka dicurigai nyeri tersebut merupakan dysmenorrhea sekunder yang terjadi karena kelainan atau penyakit pada sistem reproduksi. ${ }^{17}$

Hasil penelitian ini menunjukkan bahwa mahasiswi yang mengalami gangguan menstruasi sebagian besar cukup aktif secara fisik (61\%). Hal tersebut sejalan dengan hasil penelitian Sianipar et al yaitu dua pertiga dari responden yang mengalami gangguan menstruasi memiliki aktifitas fisik yang cukup. Penelitian tersebut juga menggunakan kriteria aktivitas fisik dari WHO yang hanya membedakan seseorang aktif atau tidak. ${ }^{5}$

Semakin tinggi intensitas dan frekuensi aktifitas fisik yang dikerjakan, maka semakin besar kemungkinan terjadi gangguan menstruasi. Aktivitas fisik dengan intensitas tinggi meningkatkan risiko gangguan menstruasi, sedangkan aktivitas fisik intesitas sedang menurunkan risiko gangguan menstruasi. ${ }^{5}$ Pada penelitian ini tidak dapat dibedakan intensitas maupun frekuensi aktivitas fisik yang dilakukan oleh responden.

Hasil uji statistik menggunakan chi-square tidak ditemukan adanya hubungan yang bermakna antara aktivitas fisik dengan gangguan menstruasi ( $p=0,846)$. Pada penelitian Amaza et al dinyatakan bahwa tidak ada hubungan antara aktivitas fisik dan dysmenorrhea pada mahasiswa kedokteran di Nigeria. Penelitian tersebut menggunakan kuisioner yang bertujuan untuk mendapatkan data mengenai usia menarche, pola menstruasi, dysmenorrhea, status perkawinan, olahraga, BMI dan diet. Data tersebut hanya dysmenorrhea yang dihubungkan dengan aktivitas fisik dan didapatkan nilai $p=0,38 .{ }^{18}$

Pada penelitian Kroll juga tidak ditemukan hubungan antara aktivitas fisik dan gangguan menstruasi pada wanita di Universitas Massachusetts (95\% Cl: 0,94-1,14). Penelitian ini dilakukan pada 186 wanita berusia 18-30 tahun. Gangguan menstruasi yang diteliti oleh Kroll hanyalah sindrom premenstruasi. $^{14}$

Hasil yang berbeda ditunjukkan oleh penelitian Gudmundsdottir et al yang menyatakan bahwa terdapat hubungan antara aktivitas fisik rekreasi dengan gangguan menstruasi pada wanita premenopause di Norwegia. Penelitian ini melibatkan 3097 wanita dengan usia 20-45 tahun. Aktivitas fisik yang diukur adalah Leisure Time Physical Activity (LTPA) atau bisa disebut juga aktivitas fisik rekreasi. Gangguan menstruasi yang diteliti pada penelitian tersebut adalah oligomenorrhea, polimenorrhea dan amenorrhea primer. Berdasarkan penelitian tersebut didapatkan hasil yaitu terjadi peningkatan panjang 
siklus pada wanita usia $>25$ tahun dengan frekuensi LTPA yang lebih tinggi dan terjadi pemendekan siklus, peningkatan lama perdarahan dan ketidakteraturan siklus pada wanita usia 20-25 tahun yang lebih aktif (OR 4,7; 95\% Cl = 1,2-18,0). Terjadi penurunan masa menstruasi pada wanita usia lebih muda dengan durasi LTPA yang lebih lama $(p<0,05)$ dan intensitas LTPA yang lebih tinggi $(p=0,065) .{ }^{19}$

Pada dua studi kohort yang dilakukan oleh Sternfeld et al ditemukan hubungan antara aktivitas fisik dan gangguan menstruasi. Penelitian ini dilakukan pada kelompok wanita yang bekerja pada industri semikonduktor dan pada wanita yang berpartisipasi pada Michigan Bone Health Study. Dari penelitian Semikonduktor didapatkan bahwa peningkatan aktivitas fisik harian berat selama 10 menit perhari akan memperpanjang lama siklus sebanyak dua persepuluh dari panjang siklus menstruasi saat itu $(p<0,05)$. Kelompok Michigan juga menunjukkan hubungan yang signifikan secara statistik antara aktivitas fisik rekreasi berat dan panjang siklus menstruasi $(p=0,008) .^{20}$

\section{KESIMPULAN}

Gangguan menstruasi terjadi pada 73,3\% mahasiswi dengan gangguan yang paling sering terjadi yaitu dysmenorrhea sebanyak $63,3 \%$. Sebagian besar mahasiswi tersebut memiliki aktivitas fisik harian yang cukup menurut rekomendasi WHO yaitu sebanyak $60 \%$. Tidak terdapat hubungan antara aktivitas fisik harian dengan gangguan menstruasi.

\section{UCAPAN TERIMA KASIH}

Terima kasih kepada semua pihak atas bimbingan, saran dan bantuannya.

\section{DAFTAR PUSTAKA}

1. Guyton AC, Hall JE. Textbook of medical physiology. Edisi ke-11, China: Elsevier; 2006.

2. Manuaba IBG. Penuntun kepaniteraan klinik obstetrik dan ginekologi. Edisi ke-2, Jakarta: EGC; 2003.

3. Montoya JS, Cabezza AH, Rojas OM, Navarrete $\mathrm{RC}$, Keever MAV. Topics in pediatrics: Menstrual disorders in adolescents. Bol Med Hosp Infant Mex. 2012;69(1):60-72.

4. Lee LK, Chen PCY, Lee KK, Kaur J. Menstruation among adolescent girls in Malaysia: a crosssectional school survey. Singapore Med J. 2006; 47(10): 869-74.

5. Sianipar O, Bunawan NC, Almazini P, Calista N, Wulandari P, Rovenska N, et al. Prevalensi gangguan menstruasi dan faktor-faktor yang berhubungan pada siswi SMU di Kecamatan Pulo Gadung Jakarta Timur. Maj Kedoktr Indon. 2009; 59(7):308-13.

6. Herrmann MA, Rockoff JE. Do menstrual problems explain gender gaps in absenteeism and earnings? Journal of Human Resources. 2012;47(2):493-508.

7. Sinha R, Kapoor AK, Kapoor S. Adiposity measures and menstrual cycle: Do we envisage a relation? Journal of Anthropology. 2011;2011:1-5.

8. Thein-Nissenbaum JM, Carr KE. Female athlete triad syndrome in the high school athlete. Physical Therapy in Sport. 2011;12:108-16.

9. U.S. Departement of Health and Human Services. Physical activity and health: $A$ report of the surgeon general executive summary. Atlanta, GA: U.S Dept. Of Health and Human Services. Centers for Disease Control and Prevention, S/N: 017-02300196-5, 1996.

10. Macniven R, Bauman A, Abouzeid M. A review of population-based prevalence studies of physical activity in adults in the Asia-Pacific region. BMC Public Health. 2012;12:41.

11. Fajaryati N. Hubungan kebiasaan olahraga dengan dismenore primer remaja putri di SMP N 2 Mirit Kebumen. Jurnal Komunikasi Kesehatan. 2012;3 (1):1-11.

12. Wojtyła A, Kapka-Skrzypczak L, Biliński P, Paprzycki P. Physical activity among women at reproductive age and during pregnancy (Youth Behavioural Polish Survey - YBPS and Pregnancy-related Assessment Monitoring Survay - PrAMS) - epidemiological population studies in Poland during the period 2010-2011. Annals of Agricultural and Environmental Medicine. 2011;18 (2):365-74 
13. Jasienzka G, Ziomkiewicz, Thune I, Lipson SF. Habitual physical activity and estradiol levels in women of reproductive age. European Journal of Cancer Prevention. 2006;15:439-45.

14. Kroll AR. Recreational physical activity and premenstrual syndrome in college-aged women (master theses). Massachusetts: University of Massachusetts; 2010.

15. Rigon F, Sanctis VD, Bernasconi S, Bianchin L, Bona G, Bozzola M, et al. Menstrual pattern and menstrual disorder among adolescents: An update of the italian data. Italian Journal of Pediatrics. 2012; 38:38.

16. Rianda AS. Gambaran gangguan haid pada mahasiswi fakultas kedokteran univesitas sumatera utara tingkat I angkatan 2010 (skripsi). Medan: Universitas Sumatra Utara; 2011.
17. Dawood MY. Primary dysmenorrhea: Advances in pathogenesis and management. Clinical Expert Series. 2006;108(2):428-41.

18. Amaza DS, Sambo N, Zirahei JV, Dalori MB, Japhet $H$, Toyin $H$. Menstrual pattern among female medical students in university of maiduguri, nigeria. British Journal of Medicine \& Medical Research. 2012; 2 (3): 327-37.

19. Gudmundsdottir SL, Flanders WD, Augestad LB. A longitudinal study of physical activity and menstrual cycle characteritics in healthy noerwegian womenThe nortronderlag health study. Norsk Epidemiology. 2011; 20(2):163-71.

20. Sternfeld B, Jacobs MK, Quesenberry CP, Gold EB, Sowers M. Physical activity and menstrual cycle characteristics in two prospective cohorts. American Journal of Epidemiology. 2002;156(5): 402-9. 